\title{
Germinação de Sementes de Plantas Daninhas de Pastagens Cultivadas: Mimosa pudica E Ipomoea asarifolia
}

\author{
Seed Germination of Weeds from Cultivated Pasture Areas: Mimosa pudica and \\ Ipomoea asarifolia
}

\begin{abstract}
SOUZA FILHO, A.P.S. ${ }^{2}$, ALVES, S.M. ${ }^{2}$, FIGUEIREDO, F.J.C. ${ }^{2}$ e DUTRA, S. ${ }^{2}$
RESUMO - Malícia (Mimosa pudica) e salsa (Ipomoea asarifolia) são importantes plantas daninhas que infestam áreas de pastagens cultivadas da região amazônica brasileira. Neste trabalho foram analisados os efeitos de fatores relacionados ao solo e clima na variação da germinação (percentual e índice de velocidade de germinação - IVG) de sementes dessas espécies. A germinação foi monitorada em um período de 15 dias, com contagens diárias e eliminação das sementes germinadas. Os resultados mostraram que os fatores de solo alumínio, pH, cálcio e magnésio não influenciam a germinação das duas espécies de plantas daninhas. A germinação das sementes de malícia e salsa pode ocorrer tanto na presença como na ausência de luz. A temperatura ótima de germinação (percentual e IVG) para ambas as espécies foi de $30{ }^{\circ} \mathrm{C}$ contínua e $25-35^{\circ} \mathrm{C}$ alternada, embora as sementes de malícia tenham germinado satisfatoriamente em temperaturas contínuas superiores e inferiores a $30{ }^{\circ} \mathrm{C}$ e em todas as combinações de temperaturas alternadas. Comparativamente, o índice de velocidade de germinação (IVG) foi mais sensível aos efeitos da temperatura do que o percentual de germinação. Ambas as espécies responderam negativamente ao aumento da salinidade, sendo a espécie malícia mais tolerante ao sal do que a salsa.
\end{abstract}

Palavras-chave: malícia, salsa, temperatura, luz, salinidade.

\begin{abstract}
Mimosa pudica and Ipomoea asarifolia are important weeds of cultivated pasture in the Brazilian Amazon Region. This research analyzes the effects of the change in soil and climate factors on the germination (percentage and germination speed index) of these species. Germination was monitored for a 15-day period, with daily counting and elimination of the germinated seeds. The results showed that soil factors such as aluminum, $\mathrm{pH}$, calcium, and magnesium did not influence the germination of the two weed species. The germination of both M. pudica and I. asarifolia is independent of light exposure. Optimum germination (percentage and germination speed index) temperature for both species was continuous, at $30{ }^{\circ} \mathrm{C}$ or alternated $25-35{ }^{\circ} \mathrm{C}$ temperature, even though the M. pudica seeds germinated satisfactorily in continuous temperature above and under $30^{\circ} \mathrm{C}$, and in all combinations of alternated temperatures. Comparatively, the germination speed index was more sensitive to the effects of the temperature than the germination percentage. Both species responded negatively to the increase in salt concentration, with $\boldsymbol{M}$. pudica being more tolerant to salt than I. asarifolia.
\end{abstract}

Key words: Mimosa pudica, Amazon, temperature, light, salinity.

Recebido para publicação em 14/3/2000 e na forma revisada em 26/1/2001.

Pesquisadores da Embrapa Amazônia Oriental, Trav. Dr. Enéas Pinheiro, S/N, 66095-100 Belém-PA.

Planta Daninha, Viçosa-MG, v.19, n.1, p.23-31, 2001 


\section{INTRODUÇÃO}

Na região amazônica brasileira, as áreas de pastagens cultivadas têm sido invadidas por uma comunidade de plantas daninhas extremamente diversificada e agressiva, chamada regionalmente de "juquira". A principal conseqüência desse fato tem sido o aumento dos custo de manutenção da atividade - notadamente com relação à limpeza da pastagem - e, em alguns casos, o abandono da área quando a infestação atinge índices elevados. Entre os mecanismos de adaptação manifestados por essas plantas está a alta produção de sementes. Deuber (1992) apresentou vários exemplos do alto potencial de produção de sementes das espécies de plantas daninhas, com destaque para Sonchus oleraceus, com 400 mil sementes por planta; Amaranthus spp., com 120 mil; e Solanum americanum, com 178 mil.

Ao serem liberadas para o meio ambiente, vão formar o banco de sementes, constituindose em verdadeiro reservatório de suprimento constante de novos indivíduos indesejáveis para as pastagens cultivadas ao longo do tempo. As flutuações na germinação dessa população de sementes são reguladas por um conjunto de fatores que, em maior ou menor escala, influenciam a taxa de emergência e, conseqüentemente, a dinâmica populacional. Fatores relacionados às condições de solo, como $\mathrm{pH}$ e nível salino, e outros relativos ao clima, como temperatura e luz, têm sido apontados como controladores da germinação das sementes no campo (MacDonald et al., 1992; Perez \& Prado, 1993; Villiers et al., 1994; Mosjidis \& Zhang, 1995; entre outros). Entretanto, variações na intensidade de resposta são observadas em função da espécie estudada.

O entendimento do comportamento da germinação das sementes de espécies de plantas daninhas em relação a fatores ambientais representa importante papel na interpretação do comportamento ecológico das espécies no campo, ao mesmo tempo que possibilita o desenvolvimento de estratégias de redução do potencial do banco de sementes nas áreas de pastagens cultivadas, com conseqüente desaceleração no suprimento de novos indivíduos de plantas indesejáveis à produtividade e estabilidade das pastagens.
A presente pesquisa teve por objetivo determinar as variações que ocorrem na germinação (percentual e índice de velocidade de germinação) de sementes das plantas daninhas de áreas de pastagens cultivadas, malícia e salsa, em resposta a fatores relacionados ao solo e clima.

\section{MATERIAL E MÉTODOS}

Sementes das plantas daninhas de pastagens cultivadas, malícia (Mimosa pudica) e salsa (Ipomoea asarifolia) foram coletadas em áreas de fazendas particulares no município de Castanhal, Estado do Pará, durante o ano de 1998, e passaram por processo de limpeza e tratamento para quebra de dormência - imersão em ácido sulfúrico por 15 e 20 minutos para malícia e salsa, respectivamente (Souza Filho et al., 1998a) -, sendo posteriormente acondicionadas em sacos de plástico até o momento de serem utilizadas.

\section{pH}

A influência do $\mathrm{pH}$ sobre a germinação das sementes foi investigada para valores de 3,0; 5,0; 7,0; 9,0; e 11,0. Para obter esses valores, foi adicionado hidróxido de potássio $(\mathrm{KOH})$ ou ácido clorídrico $(\mathrm{HCl})$ à água destilada (Mayeux \& Scifres, 1978), em quantidade suficiente para elevar ou baixar o $\mathrm{pH}$, sendo a aferição realizada com um potenciômetro.

\section{Alumínio}

Na investigação dos efeitos do alumínio, utilizaram-se soluções aquosas de $\mathrm{Al}_{2}\left(\mathrm{SO}_{4}\right)_{3} \cdot 18 \mathrm{H}_{2} \mathrm{O}$, nas concentrações de 0,$0 ; 0,5 ; 1,0 ; 1,5 ; \mathrm{e}$ 2,0 meq $100 \mathrm{ml}^{-1}$.

\section{Estresse salino}

Na análise dos efeitos da salinidade, prepararam-se soluções aquosas de $\mathrm{NaCl}$ nas seguintes concentrações: $0,25,75,150$ e $300 \mathrm{mM}$. O tratamento 0 , considerado testemunha, constou apenas de água destilada.

\section{Cálcio e magnésio}

Foram preparadas soluções aquosas de $\mathrm{CaCl}_{2}$ e $\mathrm{MgCl}_{2}$ nas concentrações de: cálcio - 
0,$0 ; 1,5 ; 3,0 ; 4,5$; e 6,0 meq $100 \mathrm{ml}^{-1}$, correspondendo, respectivamente, a 0,$0 ; 17,4 ; 22,5$; 33, 1; e 44,0 mmho; e magnésio - 0,0; 3,0; 6,0; 9,0; e 12,0 meq $100 \mathrm{ml}^{-1}$, correspondendo, respectivamente, a 0,$0 ; 26,7 ; 43,1 ; 58,7$; e 74,5 mmho.

Os efeitos anteriormente descritos foram avaliados colocando-se as sementes das duas espécies de plantas daninhas para germinar sobre duas folhas de papel-filtro umedecido com $10 \mathrm{ml}$ da respectiva solução. Diariamente, substituía-se o papel-filtro e adicionavam-se $10 \mathrm{ml}$ da solução correspondente. A temperatura foi de $30{ }^{\circ} \mathrm{C}$ constante, e o fotoperíodo, de 12 horas.

\section{Luz}

As sementes foram postas para germinar em períodos de exposição à luz de 0,$0 ; 6,0 ; 12$; 18; e 24 horas de luz. O período de 0,0 hora foi obtido revestindo-se as caixas de gerbox com papel-alumínio. A luz foi fornecida por quatro lâmpadas fluorescentes de 20 watts. A temperatura foi de $30^{\circ} \mathrm{C}$ constante.

\section{Temperatura}

Os efeitos foram analisados tendo por base as temperaturas contínuas de 20,25, 30, 35 e $40{ }^{\circ} \mathrm{C}$ e as temperaturas alternadas de $20-40$, 20-35, 25-40 e $25-35{ }^{\circ} \mathrm{C}$ para diurnos e noturnos, respectivamente. O fotoperíodo foi o mesmo para todos os ensaios: 12 horas. A germinação foi monitorada em períodos de 15 dias, com contagens diárias e eliminação das sementes germinadas. A germinação foi analisada sob dois aspectos: percentual e índice de velocidade de germinação (IVG). O IVG foi calculado tendo por base a equação proposta por Wardle et al. (1991), como segue:

$$
\mathrm{IVG}=\left[\mathrm{N}_{1} / 1+\mathrm{N}_{2} / 2+\mathrm{N}_{3} / 3+\ldots+\mathrm{N}_{\mathrm{n}} / \mathrm{n}\right] .100
$$

em que $\mathrm{N}_{1}, \mathrm{~N}_{2}, \mathrm{~N}_{3}$ e $\mathrm{N}_{\mathrm{n}}$ são as proporções de sementes germinadas no primeiro, segundo, terceiro e enésimo dias após a semeadura. Assim, o IVG pode variar de 0 (se nenhuma semente germinar) a 100 (se todas as sementes germinarem no primeiro dia).

Em todos os estudos foram utilizadas 50 sementes por caixa gerbox transparente de
$11 \times 11 \mathrm{~cm}$. Considerou-se semente germinada a que apresentava extensão radicular igual ou superior a $2 \mathrm{~mm}$ (Juntila, 1976; Duran \& Tortosa, 1985).

\section{Análise estatística}

Para todos os estudos, foram utilizados o delineamento experimental inteiramente casualizado, com três repetições. Os dados foram analisados pelo teste $\mathrm{F}$, e as médias, comparadas pelo teste de Tukey (5\%). Os efeitos do estresse salino foram analisados por regressão polinomial. Todas as análises foram realizadas pelo sistema SAS (SAS, 1989).

\section{RESULTADOS E DISCUSSÃO}

\section{pH}

A germinação das sementes das duas espécies não foi afetada $(p>0,05)$ pela variação do $\mathrm{pH}$ na faixa de 3,0 a 11,0 (Tabela 1). As informações disponíveis na literatura, em que os efeitos do $\mathrm{pH}$ sobre a germinação de sementes são analisados, são extremamente limitadas. Quando se consideram os efeitos sobre plantas daninhas, estes são praticamente inexistentes. Entre as informações disponiveis, Souza Filho et al. (1998b), em estudo de mesma natureza, também não encontraram variações na germinação das plantas daninhas malva (Urena lobata) e mata-pasto (Cassia tora). Entretanto, algumas informações disponiveis mostram que condições de meio extremamente ácido ou alcalino afetam a germinação de sementes (Batra \& Kumar, 1993; Roy, 1986). Neste trabalho, tais efeitos não foram observados. Em trabalho desenvolvido por Everitt (1983), foi constatado que a germinação das sementes de duas leguminosas foi inibida em condições de $\mathrm{pH}$ igual ou inferior a 2 e igual ou superior a 12, não tendo sido relatados efeitos negativos para valores de $\mathrm{pH}$ no intervalo de 3,0 a 11,0 .

As plantas podem tolerar variações do $\mathrm{pH}$ no meio ambiente onde se desenvolvem no intervalo de 4,0 a 8,0. Nas condições ambientais em que o $\mathrm{pH}$ esteja acima ou abaixo desses extremos, altas concentrações de $\mathrm{H}^{+}$e $\mathrm{OH}^{-}$ podem ser diretamente tóxicas para as plantas (Arnon \& Johnson, 1942). Considerando que 
no presente trabalho a germinação não foi afetada pela variação do $\mathrm{pH}$ na faixa de 3,0 a 11,0 , aparentemente condições extremas de acidez ou alcalinidade podem ser mais restritivas ao desenvolvimento das plantas do que a germinação das sementes. De outra forma, o fato de a germinação das sementes de malícia e salsa ocorrer satisfatoriamente tanto em meio ácido como alcalino não é um indicativo de que essas espécies terão a mesma habilidade adaptativa para vegetar em condições semelhantes.

Tabela 1 - Variações na germinação (\%) de sementes de plantas daninhas em função do $\mathrm{pH}$

\begin{tabular}{|c|c|c|}
\hline \multirow{2}{*}{ Valores de $\mathrm{pH}$} & \multicolumn{2}{|c|}{ Plantas daninhas } \\
\cline { 2 - 3 } & Malícia & Salsa \\
\hline 3 & $93,0 \mathrm{a}$ & $86,0 \mathrm{a}$ \\
5 & $93,0 \mathrm{a}$ & $86,0 \mathrm{a}$ \\
7 & $95,0 \mathrm{a}$ & $85,0 \mathrm{a}$ \\
9 & $94,0 \mathrm{a}$ & $87,0 \mathrm{a}$ \\
11 & $93,0 \mathrm{a}$ & $84,0 \mathrm{a}$ \\
\hline CV $(\%)$ & 3,3 & 3,8 \\
\hline DMS & 3,12 & 3,02 \\
\hline
\end{tabular}

- Médias seguidas de letras iguais, na coluna, não diferem pelo teste de Tukey (5\%).

\section{Alumínio}

Os dados da Tabela 2 mostram que a variação do teor de alumínio entre 0,0 e 2,0 meq $100 \mathrm{ml}^{-1}$ não efetivou variações ( $p>0,05)$ na germinação das sementes das plantas salsa e malícia. Existem poucas informações disponiveis onde são analisados os efeitos do alumínio na germinação de sementes. No entanto, o fato de o alumínio afetar os processos do metabolismo celular, como aqueles relacionados com a síntese protéica, permeabilidade à água, mobilização de lipídios, divisão celular e síntese da parede celular (Roy et al., 1988), é um indicativo de que esse íon pode afetar a germinação de sementes. Um exemplo dessa possibilidade foi apresentado por Brassard et al. (1988), no qual a concentração de alumínio de $0,15 \mathrm{meq} 100 \mathrm{ml}^{-}$ ${ }^{1}$ inibiu a germinação de sementes de coníferas.

Os resultados obtidos neste trabalho mostram que as plantas invasoras malícia e salsa têm habilidade para germinar satisfatoriamente em ambientes com concentração de alumínio variando de 0,0 a 2,0 meq $100 \mathrm{ml}^{-1}$.

Tabela 2 - Variações na germinação (\%) de sementes de plantas daninhas em função do teor de alumínio

\begin{tabular}{|c|c|c|}
\hline \multirow{2}{*}{$\begin{array}{c}\text { Alumínio } \\
\left(\text { meq } 100 \mathrm{ml}^{-1}\right)\end{array}$} & \multicolumn{2}{|c|}{ Plantas daninhas } \\
\cline { 2 - 3 } & Malícia & Salsa \\
\hline 0,0 & $95,0 \mathrm{a}$ & $84,0 \mathrm{a}$ \\
0,5 & $96,0 \mathrm{a}$ & $83,0 \mathrm{a}$ \\
1,0 & $94,0 \mathrm{a}$ & $84,0 \mathrm{a}$ \\
1,5 & $94,0 \mathrm{a}$ & $85,0 \mathrm{a}$ \\
2,0 & $95,0 \mathrm{a}$ & $83,0 \mathrm{a}$ \\
\hline CV $(\%)$ & 3,0 & 2,8 \\
\hline DMS & 2,19 & 2,98 \\
\hline
\end{tabular}

Médias seguidas de letras iguais, na coluna, não diferem pelo teste de Tukey (5\%).

\section{Cálcio e magnésio}

As sementes de malícia e salsa foram capazes de germinar uniformemente $(p>0,05)$ em ambientes com concentrações de cálcio variando de 0,0 a 6,0 meq $100 \mathrm{ml}^{-1}$ (Tabela 3) e de magnésio com concentração na faixa de 0,0 a 12,0 meq $100 \mathrm{ml}^{-1}$ (Tabela 4). Embora em número reduzido, os trabalhos disponiveis na literatura mostram que determinados cátions, como o $\mathrm{Mg}^{++}$e o $\mathrm{Ca}^{++}$, podem afetar a germinação de sementes das plantas superiores em maior ou menor escala (Ryan et al., 1975; Rumbaugh et al., 1993), podendo o efeito depressivo variar em função da espécie de planta em estudo e da concentração em que esses cátions são encontrados. Everitt et al. (1983) estudaram os efeitos de diferentes sais, entre eles sais de cálcio e de magnésio, em concentração variando de 16 a 40 mmho de condutividade elétrica, não verificando qualquer efeito dos sais sobre a germinação de sementes de Kochia scoparia até valores de 20 mmho de condutividade. Entretanto, a partir desse valor, a germinação foi reduzida progressivamente até o nivel mais alto de condutividade.

As diferentes concentrações de cálcio e magnésio expressas em meq $100 \mathrm{ml}^{-1}$ (Tabelas 3 e 4) foram convertidas em mmho por meio de um condutivímetro. Os valores mínimos e 
máximos obtidos foram de 0 e 44,0 mmho para concentrações de 0 e 6,0 meq $100 \mathrm{ml}^{-1}$ de cálcio e de 0 e 64,5 mmho para concentrações de 0,0 e 12,0 meq $100 \mathrm{ml}^{-1}$ de magnésio, respectivamente. Aparentemente, e ao contrário dos resultados anteriormente descritos na literatura para outras espécies, as sementes de malícia e salsa apresentaram capacidade para germinar satisfatoriamente em condições de concentrações de cálcio na faixa de até $6,0 \mathrm{meq} 100 \mathrm{ml}^{-1}$, e de magnésio, de até 12,0 meq $100 \mathrm{ml}^{-1}$.

Tabela 3 - Variações na germinação (\%) de sementes de plantas daninhas em função do teor de cálcio

\begin{tabular}{|c|c|c|}
\hline \multirow{2}{*}{$\begin{array}{c}\text { Teor de Ca } \\
\left(\text { meq } 100 \mathrm{ml}^{-1}\right)\end{array}$} & \multicolumn{2}{|c|}{ Plantas daninhas } \\
\cline { 2 - 3 } & Malícia & Salsa \\
\hline 0,0 & $95,0 \mathrm{a}$ & $81,0 \mathrm{a}$ \\
1,5 & $93,0 \mathrm{a}$ & $79,0 \mathrm{a}$ \\
3,0 & $95,0 \mathrm{a}$ & $79,0 \mathrm{a}$ \\
4,5 & $93,0 \mathrm{a}$ & $81,0 \mathrm{a}$ \\
6,0 & $94,0 \mathrm{a}$ & $81,0 \mathrm{a}$ \\
\hline CV $(\%)$ & 3,3 & 4,0 \\
\hline DMS & 2,78 & 3,01 \\
\hline
\end{tabular}

- Médias seguidas de letras iguais, na coluna, não diferem pelo teste de Tukey $(5 \%)$.

Tabela 4 - Variações na germinação (\%) de sementes de plantas daninhas em função do teor de magnésio

\begin{tabular}{|c|c|c|}
\hline \multirow{2}{*}{$\begin{array}{c}\left.\text { Teor de } \mathrm{Mg}^{-1} \text { (meq } 100 \mathrm{ml}^{-1}\right)\end{array}$} & \multicolumn{2}{|c|}{ Plantas daninhas } \\
\hline & Malícia & Salsa \\
\hline 0,0 & $95,0 \mathrm{a}$ & $83,0 \mathrm{a}$ \\
\hline 3,0 & $94,0 \mathrm{a}$ & $83,0 \mathrm{a}$ \\
\hline 6,0 & $94,0 \mathrm{a}$ & $81,0 \mathrm{a}$ \\
\hline 9,0 & $95,0 \mathrm{a}$ & $82,0 \mathrm{a}$ \\
\hline 12,0 & $93,0 \mathrm{a}$ & $81,0 \mathrm{a}$ \\
\hline $\mathrm{CV}(\%)$ & 2,5 & 3,0 \\
\hline DMS & 1,98 & 2,72 \\
\hline
\end{tabular}

Médias seguidas de letras iguais, na coluna, não diferem pelo teste de Tukey (5\%).

\section{Tempo de duração de luz}

A variação do tempo de duração da luz de 0 a 24 horas não propiciou variações ( $p>0,05)$ na germinação das sementes das duas espécies de plantas daninhas (Tabela 5). Esses resultados parecem indicar que o tempo de exposição das sementes à luz não é fator determinante na germinação das sementes de malícia e malva, podendo estas germinarem tanto em condições de ausência total de luz como na presença de luz por até 24 horas.

Tabela 5 - Variações na germinação (\%) de sementes de plantas daninhas em função do tempo de duração da luz

\begin{tabular}{|c|c|c|}
\hline \multirow{2}{*}{$\begin{array}{c}\text { Duração da luz } \\
\text { (horas) }\end{array}$} & \multicolumn{2}{|c|}{ Plantas daninhas } \\
\cline { 2 - 3 } & Malícia & Salsa \\
\hline 0 & $97,0 \mathrm{a}$ & $79,0 \mathrm{a}$ \\
6 & $96,0 \mathrm{a}$ & $80,0 \mathrm{a}$ \\
12 & $94,0 \mathrm{a}$ & $79,0 \mathrm{a}$ \\
18 & $95,0 \mathrm{a}$ & $78,0 \mathrm{a}$ \\
24 & $96,0 \mathrm{a}$ & $80,0 \mathrm{a}$ \\
\hline CV (\%) & 2,6 & 4,6 \\
\hline DMS & 4,50 & 4,43 \\
\hline
\end{tabular}

- Médias seguidas de letras iguais, na coluna, não diferem pelo teste de Tukey (5\%).

A luz tem sido reconhecida como um requerimento para a germinação de sementes de muitas espécies de plantas daninhas (Black, 1969). Entretanto, dependendo da capacidade de adaptação às condições ambientais, as plantas podem ter distintas respostas à luz ambiental tanto em termos de quantidade como de qualidade (Givnish, 1988; Seemann, 1989). Santos \& Pereira (1987) mostram que, quanto à luz, as plantas podem ser fotoblásticas positivas ou negativas, conforme a germinação seja promovida ou inibida pela luz, existindo ainda espécies cujas sementes se mostram indiferentes à presença de luz para germinar. A ausência de resposta da germinação à variação no tempo de duração da luz enquadra as espécies malícia e salsa no grupo de plantas que não têm na luz requerimento essencial para que suas sementes germinem.

\section{Temperatura}

A germinação das sementes das duas espécies de plantas daninhas estudadas variou $(\mathrm{p}<0,05)$ em função da temperatura contínua (Tabela 6). As sementes de malícia germinaram sempre acima de 90\% em condições de temperatura contínua na faixa de 25 a $35{ }^{\circ} \mathrm{C}$. Em temperaturas de $20^{\circ} \mathrm{C}$, a germinação foi no mínimo 54\% menor, e em temperatura de 
$40{ }^{\circ} \mathrm{C}, 26 \%$ menor do que aqueles valores obtidos para temperaturas de 25 a $35^{\circ} \mathrm{C}$, o que indica que temperaturas baixas são mais restritivas à germinação (\%) do que temperaturas altas. Para a salsa, a germinação atingiu seu melhor resultado à temperatura contínua de $30{ }^{\circ} \mathrm{C}$; valores abaixo ou superiores resultaram em reduções na germinação. Ao contrário dos efeitos observados na germinação das sementes de malícia, temperaturas baixas ou altas promoveram respostas similares da germinação. Esses resultados indicam que a salsa tem maiores exigências no que se refere à temperatura para germinação do que a malícia, que apresenta faixa mais ampla no tocante à exigência de temperatura para germinação máxima.

Semelhantemente aos efeitos observados na germinação (\%), o IVG também variou $(\mathrm{p}<0,05)$ em função da temperatura contínua (Tabela 6). No entanto, as variações observadas foram de maior amplitude do que aquelas observadas no percentual de germinação. Para malícia, por exemplo, enquanto a germinação (\%) não variou $(\mathrm{p}<0,05)$ na faixa de 25 a $35^{\circ} \mathrm{C}$, o IVG diferiu $(\mathrm{p}<0,05)$ nesse mesmo intervalo. Tanto para malícia como para salsa, o IVG atingiu valor máximo a $30{ }^{\circ} \mathrm{C}$. Temperaturas abaixo ou acima deste valor promoveram reduções no IVG. Repetindo os efeitos observados sobre o percentual de germinação, temperaturas menores que àquelas onde foram observados máximo IVG foram mais restritivas ao IVG para malícia do que temperaturas altas, enquanto para salsa os efeitos foram semelhantes.

Tabela 6 - Variações na germinação de sementes de plantas daninhas em função da temperatura contínua

\begin{tabular}{|c|c|c|c|c|}
\hline \multirow{2}{*}{$\begin{array}{c}\text { Temperatura } \\
\left({ }^{\circ} \mathrm{C}\right)\end{array}$} & \multicolumn{4}{|c|}{ Plantas daninhas } \\
\cline { 2 - 5 } & $\begin{array}{c}\text { Malícia } \\
\text { Germi- } \\
\text { nação } \\
(\%)\end{array}$ & IVG & $\begin{array}{c}\text { Germi- } \\
\text { nação } \\
(\%)\end{array}$ & IVG \\
\hline 20 & $42,0 \mathrm{c}$ & $4,89 \mathrm{e}$ & $40,0 \mathrm{~d}$ & $20,00 \mathrm{~d}$ \\
25 & $94,0 \mathrm{a}$ & $49,53 \mathrm{~b}$ & $71,0 \mathrm{~b}$ & $41,00 \mathrm{~b}$ \\
30 & $92,0 \mathrm{a}$ & $62,00 \mathrm{a}$ & $84,0 \mathrm{a}$ & $54,00 \mathrm{a}$ \\
35 & $94,0 \mathrm{a}$ & $44,39 \mathrm{c}$ & $64,0 \mathrm{c}$ & $33,67 \mathrm{c}$ \\
40 & $68,0 \mathrm{~b}$ & $21,61 \mathrm{~d}$ & $41,0 \mathrm{~d}$ & $21,33 \mathrm{~d}$ \\
\hline CV $(\%)$ & 2,6 & 3,0 & 5,3 & 5,8 \\
\hline DMS & 5,46 & 2,96 & 5,72 & 5,72 \\
\hline
\end{tabular}

- Médias seguidas de letras iguais, na coluna, não diferem pelo teste de Tukey $(5 \%)$.

Planta Daninha, Viçosa-MG, v.19, n.1, p.23-31, 2001
A germinação (\%) das sementes de malícia e salsa apresentou respostas diferenciadas em relação às diferentes combinações de temperaturas alternadas (Tabela 7). Para malícia, a germinação não foi afetada $(p>0,05)$ pela temperatura alternada, sendo a germinação, em todas as condições, superior a $80 \%$. Para salsa, a germinação (\%) em temperaturas alternadas de $20-35{ }^{\circ} \mathrm{C}$ e $25-35{ }^{\circ} \mathrm{C}$ foi superior $(\mathrm{p}<0,05)$ àquelas verificadas para $20-40^{\circ} \mathrm{C}$ ou $25-40{ }^{\circ} \mathrm{C}$. Esse resultado aponta para maior plasticidade adaptativa da malícia, que permite melhor poder de germinação das sementes em ambientes com maiores amplitudes de variação de temperatura.

Tabela 7 - Variações na germinação de sementes de plantas daninhas em diferentes temperaturas alternadas

\begin{tabular}{|c|c|c|c|c|}
\hline \multirow{2}{*}{$\begin{array}{c}\text { Temperatura } \\
\left({ }^{\circ} \mathrm{C}\right)\end{array}$} & \multicolumn{4}{|c|}{ Plantas daninhas } \\
\cline { 2 - 5 } $\begin{array}{c}\text { Noturna- } \\
\text { diurna }\end{array}$ & $\begin{array}{c}\text { Malícia } \\
\text { Germi- } \\
\text { nação } \\
(\%)\end{array}$ & IVG & $\begin{array}{c}\text { Germi- } \\
\text { nação } \\
(\%)\end{array}$ & IVG \\
\hline $20-40$ & $84,0 \mathrm{a}$ & $35,53 \mathrm{c}$ & $10,0 \mathrm{c}$ & $10,63 \mathrm{c}$ \\
$25-40$ & $81,0 \mathrm{a}$ & $45,60 \mathrm{~b}$ & $21,0 \mathrm{~b}$ & $9,04 \mathrm{c}$ \\
$20-35$ & $83,0 \mathrm{a}$ & $44,07 \mathrm{~b}$ & $64,0 \mathrm{a}$ & $16,48 \mathrm{~b}$ \\
$25-35$ & $85,0 \mathrm{a}$ & $52,43 \mathrm{a}$ & $71,0 \mathrm{a}$ & $19,83 \mathrm{a}$ \\
\hline CV $(\%)$ & 2,39 & 2,39 & 5,48 & 4,49 \\
\hline DMS & 5,94 & 2,15 & 5,79 & 2,01 \\
\hline
\end{tabular}

Médias seguidas de letras iguais, na coluna, não diferem pelo teste de Tukey (5\%).

Ao contrário dos efeitos observados no percentual de germinação, o IVG variou $(p<0,05)$ entre as diferentes combinações de temperaturas noturnas-diurnas, embora para ambas as espécies o IVG máximo tenha sido obtido na mesma faixa de temperaturas alternadas $\left(25-35^{\circ} \mathrm{C}\right)$. Comparativamente, o IVG para sementes de malícia apresentou máxima amplitude de variação de $32 \%$, enquanto para salsa a amplitude máxima foi de $70 \%$, o que confirma aqueles resultados verificados para percentual de germinação e mostra a salsa como mais sensível às variações de temperaturas noturnas-diurnas (Tabela 7). As informações disponíveis mostram que mudanças de temperatura no solo se constituem em fator responsável pelo fluxo de emergência de plântulas no solo (Roberts, 1988). Esse aspecto não 
foi verificado para malícia no tocante ao percentual de germinação, o que indica variação de respostas em função da espécie de planta.

O sucesso no estabelecimento de uma determinada espécie está na dependência da utilização da temperatura ótima para germinação. Os trabalhos de Brar et al. (1991) e Elkins et al. (1996) mostram que as plantas apresentam respostas diferenciadas às temperaturas, atingindo valores máximos em diferentes faixas. Dentro dessas faixas, pode ser considerada como temperatura ótima aquela na qual a mais alta porcentagem de germinação é obtida dentro do menor espaço de tempo. Seriam consideradas ainda a mínima e a máxima, respectivamente como a mais baixa e a mais alta temperatura onde a germinação ocorre (Mayer \& Poljakoff-Mayber, 1989). No presente trabalho, considerando os valores de germinação (\% e IVG), a temperatura ótima de germinação para as duas espécies foi a mesma: $30{ }^{\circ} \mathrm{C}$ de temperatura contínua e $25-35{ }^{\circ} \mathrm{C}$ de temperatura alternada, embora a malícia tenha apresentado maior tolerância às variações de temperatura.

Os valores de germinação (\% e IVG) obtidos no presente trabalho para as temperaturas mínima e máxima estabelecidas $\left(20\right.$ e $\left.40{ }^{\circ} \mathrm{C}\right)$ indicam que estas foram subestimadas. Aparentemente, a germinação das sementes de malícia e malva pode ocorrer em temperaturas abaixo de $20^{\circ} \mathrm{C}$ e acima de $40^{\circ} \mathrm{C}$, o que revela todo o potencial de infestação que essas plantas possuem para infestar ambientes com grandes amplitudes de variação de temperaturas.

\section{Estresse salino}

O aumento do estresse salino promoveu reduções na germinação das sementes das duas espécies de plantas daninhas (Figura 1). A análise de regressão polinomial mostrou efeitos quadráticos da concentração do sal na germinação, sendo as relações expressas pelas equações:

Malícia $\rightarrow \hat{\mathrm{Y}}=91,98+0,21 \mathrm{X}-0,002 \mathrm{X}^{2} ; \mathrm{R}^{2}=0,98 * *$

Salsa $\rightarrow \hat{\mathrm{Y}}=83,78+0,032 \mathrm{X}-0,002 \mathrm{X}^{2} ; \mathrm{R}^{2}=0,98 * *$

As espécies responderam em diferentes graus de intensidades à variação de concentração salina. Para malícia, a germinação esteve sempre acima dos 90,0\% no intervalo de 0 a $150 \mathrm{mM}$, enquanto para a salsa a germinação foi superior a $80 \%$ apenas no intervalo de 0 a $25 \mathrm{mM}$. Esses dados apontam maior plasticidade para as sementes de malícia germinar satisfatoriamente em ambientes com salinidade em nivel semelhante ao daquele intervalo. $\mathrm{Na}$ concentração de $300 \mathrm{mM}$, as duas espécies tiveram comportamento semelhante em relação à germinação das sementes, não tendo sido observada germinação para as duas espécies (Figura 1).

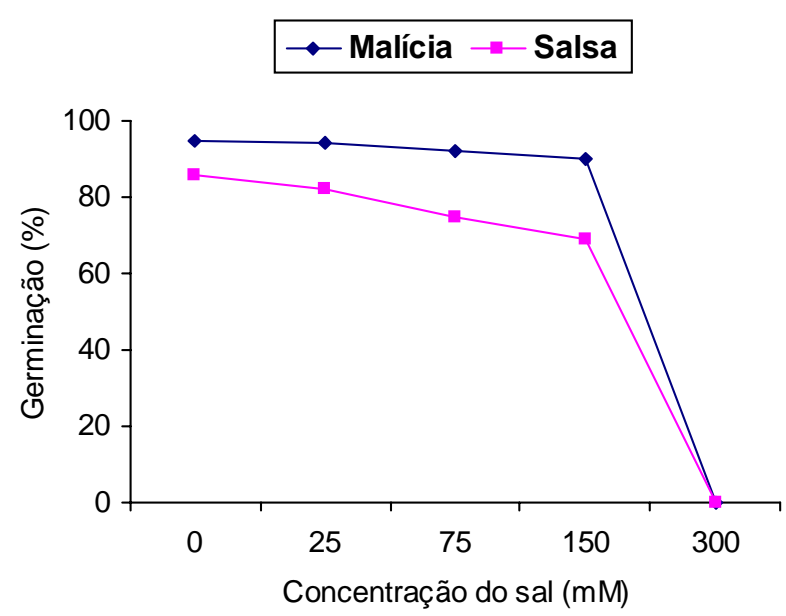

Figura 1 - Variações na germinação de sementes de plantas daninhas em função da concentração de sal.

Os efeitos deletérios da salinidade na germinação das sementes observados neste trabalho têm sido relatados por outros autores (Rogers et al., 1995; Perez \& Moraes, 1994).

A manifestação dos efeitos deletérios do sal na germinação tem sido atribuída aos efeitos osmóticos do $\mathrm{NaCl}$, limitando a hidratação das sementes, e aos efeitos tóxicos do sal no embrião ou nas células da membrana do endosperma (Bliss et al., 1986). A divisão e o alongamento celular, assim como a imobilização das reservas indispensáveis para a ocorrência do processo germinativo, também têm sido mencionados (Ferreira \& Rebouças, 1992). A salinidade pode ainda comprometer a germinação não só dificultando a absorção de água pelas sementes, como facilitando a entrada de íons em níveis tóxicos (Ayres, 1952). 
Em muitas espécies de plantas, a sensibilidade ao $\mathrm{NaCl}$ é conhecida por variar entre os diferentes estádios de crescimento. Dessa maneira, a sensibilidade da germinação evidenciada pelas duas espécies, em maior ou menor escala, à salinidade não indica necessariamente que as espécies mostrarão similar sensibilidade quando na fase de plantas adultas. Muitas espécies, como Medicago sativa e Trifolium michelianum, são substancialmente mais tolerantes à salinidade durante a fase de planta madura do que na germinação ou durante a fase inicial de crescimento (Rogers \& Noble, 1991), enquanto espécies como o T. subterraneum têm comportamento inverso (West \& Taylor, 1981). Isso posto, a superioridade das sementes de malícia em germinar em condições salinas não necessariamente é um indicativo de que esta espécie terá maior plasticidade adaptativa para vegetar nessas mesmas condições.

\section{LITERATURA CITADA}

ARNON, D.I.; JOHNSON, C.M. Influence of hydrogenion concentration on the growth of higher plants under controlled conditions. Plant Physiol., v.17, p.525-539, 1942.

AYRES, A.D. Seed germination as affected by soil moisture and salinity. Agron. J ., v.44, p.82-84, 1952.

BATRA, L.; KUMAR, A. Effects of alkalinity on germination, growth and nitrogen content of whistling (Casuarina equisetifolia) and bufwood (C. glauca). Ind. J . Agric. Sci., v.63, n.7, p.412416, 1993.

BLACK, M. Light-controlled germination of seed. Symp. Soci. Exper. Biol., v.23, p193, 1969.

BLISS, R.D.; PLATT-ALOIA, K.A.; THOMSON, W.W. The inhibitory effect of $\mathrm{NaCl}$ on barley germination. Plant, Cell Environ., v.9, p.727733, 1986.

BRAR, G.S.; GOMES, J.F.; McMICHEL, B.L.; MATCHES, A.G.; TAYLOR, H.M. Germination of twenty forage legumes as influenced by temperature. Agron. J ., v.83, p.173-175, 1991.

BRASSARD, P.; KRAMER, J.R.; NOSKO, P.; KERSHAW, A. Continuous flow rhisrtat for the study of aluminium toxicity. Plant, Cell Environ., v.11, p.863-873, 1988.
DEUBER, R. Ciência das plantas daninhas: fundamentos. Jaboticabal: FUNEP, 1992. 423p.

DURAN, R.D.; TORTOSA, M.E. The effect of mechanical and chemical scarification on germination of charlock (Sinapis arvensis L.) seeds. Seed Sci. Tecnol., v.13, n.1, p.155-163, 1985.

ELKINS, D.M.; HOVELAND, C.S.; DONNELY, E.D. Germination of Vicia species and interspecific lines as affected by temperature cycles. Crop Sci., v.6, p.45-48, 1996.

EVERITT, J.H. Seed germination characteristics of two woody legumes (retania and twested acacia) from South Texas. J . Range Manag., v.36, n.2, p.411-414, 1983.

EVERITT, J.H.; ALANIZ, M.A.; LEE, J.B. Seed germination characteristics of Kochia scoparia. J . Range Manag., v.36, n.5, p.646-448, 1983.

FERREIRA, L.G.; REBOUÇAS, M.A. Influência da hidratação/desidratação de sementes de algodão na superação dos efeitos da salinidade na germinação. Pesq. Agropec. Bras., v.27, n.4, p.609-615, 1992.

GIVNISH, T.J. Adaptation to sun and shad: a wholeplant perspective. Aust. J . Plant. Physiol., v. 15, p.63-92, 1988.

JUNTILA, O. Seed and embryo germination in S. vulgaris and $S$. reflexa as affected by temperature during seed development. Physiol. Plant., v.29, p.264-268, 1976.

MAcDONALD, G.E.; BRECK, B.J.; SHILLING, D.G. Factors affecting germination of dogfennel (Eupatorium capillifolium) and yankeeweed (E. compositifolium). Weed Sci., v.40, n.3, p.424$428,1992$.

MAYER, A.M.; POLJAKOFF-MAYBER, A. The germination of seeds. Oxford: Pergamon Press, 1989. 270p.

MAYEUX, H.S.; SCIFRES, C.J. Germination goldenweed seed. J . Range Manag., v.31, p.371$374,1978$.

MOSJIDIS, J.A.; ZHANG, X. Seed germination and root growth of several Vicia species at different temperature. Seed Sci. Technol., v.23, n.3, p.749-759, 1995.

PEREZ, S.C.; MORAES, J.A. Estresse salino no processo germinativo de algarobeira e atenuação de seus efeitos pelo uso de reguladores de crescimento. Pesq. Agropec. Bras., v.29, n.3, p.389-396, 1994. 
PEREZ, S.C.J.G.; PRADO, C.H.B.A. Efeitos de diferentes tratamentos pré-germinativos e da concentração de alumínio no processo germinativo de sementes de Copaifera langsdorffii Desv. R. Bras. Sementes, v.15, n.1, p.115-118, 1993.

ROBERTS, E.H. Temperature and seed germination. In: LONG, S.P., WOODWARD, F.I. (Eds.) Plant and temperature. Symp. Soc. Exper. Biol., v.42, p.96-128, 1988.

ROGERS, M.E.; NOBLE, C.L. The effect of NaCl on the establishment and growth of balansa clover (Trifolium michelianum Sasi. Var. Balansae Boiss.). Aust. J . Agric. Res., v.44, p.785-798, 1991.

ROGERS, M.E.; NOBLE, C.L.; HALLORAN, G.M.; NICOLAS, M.E. The effect of $\mathrm{NaCl}$ on the germination and early seedling growth of white clover (Trifolium repens L.) population selected for high and low salinity tolerance. Seed Sci. Technol., v.23, n.2, p.277-287, 1995.

ROY, M.M. Effects of $\mathrm{pH}$ on germination of Dichrostachys cinerea (L.) Weigh e Arn. J. Tree Sci., v.5, n.1, p.62-64, 1986.

ROY, A.K.; SHARMA, A.; TALUKDER, G. Some aspects of aluminium toxicity in plants. Bot. Rev., v.54, p.145-178, 1988.

RUMBAUGH, M.D.; JOHNSON, D.A.; PENDERY, B.M. Germination inhibition of alfafa by two component salt mixture. Crop Sci., v.33, n.5, p.1046-1050, 1993.

RYAN, J.; MIYAMOTO, S.; STROEHLEIN, J.L. Salt and specific ion effect on germination of four grass. J. Range Manag., v.28, n.1, p.61-64, 1975.
SANTOS, S.D.S.; PEREIRA, M.F.A. Germinação de dois cultivares de beterraba açucareira: efeito de luz e temperatura. R. Bras. Bot., v.10, p.15$20,1987$.

SAS - INSTITUTE. Statistical Analysis System. User's Guide. Version 6, SAS/Institute INC. 4.ed. North Caroline: 1989. 846p.

SEEMANN, J.R. Light adaptation acclimation of photosysthesis and carboxilase activity in sun and shade plants. Plant Physiol., v.91, p.379386, 1989.

SOUZA FILHO, A.P.S.; DUTRA, S.; SILVA, M.A.M.M. Métodos de superação da dormência de sementes de plantas daninhas de pastagens cultivadas da Amazônia. Planta Daninha, v. 16, n.1, p.3-11, 1998a.

SOUZA FILHO, A.P.S.; DUTRA, S.; SILVA, M.A.M.M.; TEIXEIRA NETO, J.F. Efeitos de diferentes substratos e da profundidade de semeadura na germinação de sementes de mata-pasto e malva. Planta Daninha, v.16, n.1, p.67-74, 1998b.

VILLIERS, A.J.; VAN ROOYEN, M.W.; THERSON, G.H.; VAN DER VENTER, H.A. Germination of three nonaqualand pioneer species as influenced by salinity, temperature and light. Seed Sci. Technol., v.22, n.3, p.427-433, 1994.

WARDLE, D.A.; AHMED, M.; NICHOLSON, K.S. Allelopathy influence of nodding thistle (Carduus nutans L.) seeds on germination and growth of pasture plants. New Zeal. J . Agric. Res., v.34, n.2, p.185-191, 1991.

WEST, D.W.; TAYLOR, J.A. Germination and growth of cultivars of Trifolium subterraneum L/ in the presence of sodium choride salinity. Plant Soil, v.62, p.221-230, 1981. 